\title{
产教融合背景下地方高校创新性应用型人才培养的探索
}

\section{宋＼cjkstart建＼cjkstart刘丽霞 曾强成}

摘要 地方高校作为创新性应用型人才培养基地, 以服务地方产业和区域经济发展为使命。产教融合是 促进校企协同育人的基本手段, 是实现产业链和专业链融合的主要途径。以产教融合推进地方高校教育质量 提升, 德州学院通过改革人才培养方案, 优化专业和课程体系, 采取多元化创新创业教育内容, 推进实践教 学, 打造实践创新平台, 培养“双师型”教师和建立人才培养保障措施, 搭建以能力提高为本位的产教融合培 养机制，为创新性应用型人才培养提供参考和借鉴。

关键词 地方高校 产教融合＼cjkstart创新性应用型人才

\section{一、引言}

从全球科技发展趋势来看, 新一轮科技革命和产业变革正在重构全球创新版图, 我国高等教育在新时期 面临产业化发展的新形势, 培养创新性人才是推动科技创新的关键因素 ${ }^{[1]}$ 。我国经济正处在转型时期, 为支撑 国家经济转型，适应新经济产业对创新性人才和应用型人才的需求。教育部提出实施“六卓越一拔尖”计划 2.0 , 强调推进新工科、新医科、新农科、新文科建设, 提升高校服务经济社会发展的能力, 推动高等教育内涵式 发展。产教融合是提高高等教育质量的重要途径, 深化产教融合, 推进协同育人已成为助力高校内涵式发展 的基本手段。其中“新工科”建设更重视产教融合协同育人，提出了加强学科交叉融合，关注产业发展趋势， 学科建设与产业界的关系, 建立校企深层次的互动, 培养工程实践能力强, 工程创新能力强的复合型新工科 人才 ${ }^{[2]}$ 。

\section{二、我国产教融合协同育人的提出与现状}

习近平总书记在十九大报告中指出“深化产教融合, 校企合作”“实现高等教育内涵式发展”, 将产教融合 提升到重要的位置。2017 年《国务院办公厅关于深化产教融合的若干意见》提出深化产教融合, 促进教育链、 人才链与产业链、创新链有机衔接, 是推进人力资源供给侧结构性改革的迫切要求。十九届四中全会决定建 立以企业为主体、市场为导向、产学研深度融合的技术创新体系。2019 年 4 月国家发展改革委、教育部发布 《建设产教融合型企业实施办法 (试行)》。同年 10 月, 国家发改委等 6 部门印发《国家产教融合建设试点实 施方案》, 提出产教融合是促进教育优先发展、人才引领发展、产业创新发展、经济高质量发展相互贯通、协 同、促进的战略性举措。国家文件迭发, 促进产教融合校企合作, 体现了产教融合已成为时代发展的潮流趋 势。然而, 地方本科院校与大多数双一流部属院校相比, 面临较严重的财政问题, 多年来许多地方本科院校 一直抱有 “化缘”的心态开展校企合作。结果导致企业积极性不高, 产教融合形式单一, 融合深度不够, 使学 校培养的人才无法满足产业和行业发展的需求。对于校企合作, 地方高校的底气来自内涵。产教融合过程中, 地方高校应加强内涵建设, 摈弃“化缘”思维, 积极开拓产教融合、校企合作的新路径、新模式。通过寻找共赢 机制，互惠共赢，才能缔结持久深入的校企合作，维持校企合作的青春永驻 ${ }^{[3]}$ 。

\section{三、地方院校迫切需要加强创新性应用型人才培养}


世界科技革命与产业变革和新经济产业对创新性应用型人才的需求十分迫切。地方高校已成为培养创新 性应用型人才的重要场所。我国的地方高校数量众多，分布广泛。其办学定位一般具有“区位特征”。人才培 养的目标以对接区域内行业和企业, 培养应用型人才为主。推进地方高校内涵式发展, 创新性应用型人才的 培养是提高人才培养质量的核心环节 ${ }^{[4]}$ 。德州学院是山东省德州市唯一一所省属本科院校, 承载着两万多本 专科人才培养的任务, 生命科学学院作为二级学院重点建设生物学优势学科专业群, 为服务地方产业特色专 业群和省级专业综合改革试点专业群。学院依托多个省级教学科研平台, 构建产学研结合的人才培养模式, 注重学生工程实践能力和创新创业能力的培养。

早在 2010 年德州市被国家工信部授予“第一批国家新型工业化示范基地”荣誉称号，成为首批 62 个示范 基地中唯一的生物产业基地、全国 22 个“国家高技术产业(生物产业)基地”中唯一以生物制造为主体的产业基 地。在基地内, 初步构建起以生物制造为主体, 生物农业、生物医药等为辅助的生物产业。同时, 德州被定 位为“一区四基地”，即京津地区南部重要生态功能区、产业转移承接基地、科技成果转化基地、优质农产品 供应基地、高素质劳动力培训输送基地。围绕京津冀经济区生物资源的合理利用，德州市在生态保护、生物 制药、农业等领域存在人才缺口, 需要一大批较高专业素养的人才投入到这些相关产业和行业的发展中来。

\section{四、产教融合作为创新性人才培养重要途径}

德州学院在转型发展过程中, 确立创新性应用型人培养的目标, 产教融合成为重要的一个落脚点。开创 产教融合的新途径, 将传统的学科专业进行继承与创新使其满足区域生物产业的需求; 将教学内容与新技术 的发展进行交叉与融合; 以利益共享机制协调办学资源，创新地方高校培养模式，支撑区域生物产业结构升 级。德州学院生命科学学院在专业设置与调整过程中, 根据国家当前的京津冀协同发展规划, 密切捕捉德州 生物产业的需求新动态, 新趋势, 进一步优化专业结构, 让传统的生物技术, 生物工程专业紧密对接“国家高 技术生物产业基地”需求，并设置食品质量与安全新专业，建设以工科为主的生物学优势学科专业群，以“新 工科”建设为契机, 培育形成学校鲜明的学科专业特色。生物学优势学科专业群建设“立足德州、面向山东”, 结合山东省和德州市生物产业的发展规划, 紧跟地方产业发展需求, 提升融入和服务地方经济社会发展的能 力。

\section{五、地方高校培养创新性应用型人才培养机制和措施}

（一）产教融合背景下创新性应用型人才培养机制

创新性应用型人才培养机制是在产教融合教育理念的指导下，由人才培养目标、培养方案、培养过程等 多种因素构成的相对稳定的教育教学过程与运行过程的总和 ${ }^{[5]}$ 。地方高校要在产教融合背景下注重学生自我 发展机制的创新。创新性应用型人才的培养既要靠外部机制，也靠内在机制，即学生自我发展机制，这是一 种基于由学生动机水平而产生的创新需求, 并形成的自我学习机制。在人才培养过程中主要体现在以下两个 方面: 一方面, 完善学校基础教学, 在校内平台进行基础知识的学习, 在公共课程和专业知识学习过程中加 大应用能力的培养, 提升学习兴趣和动力, 进而促进理论知识的理解和掌握; 另一方面, 对接产业链, 健全 需求导向的实践创新能力的提高, 在企业、校企实训平台进行实践训练。着力构建以创新能力提高为本位的 产教融合培养机制。

（二）创新性应用型人才培养过程中实施策略 
人才培养方案制定前对人才的需求源进行调查，从企业、公司等用人单位角度提出创新性应用型人才的 培养规格、质量要求和评价标准。由于企业和行业对人才需求更加具体，让企业参与课程体系制定，领办产 业特色鲜明的教学内容。具体实践课程由企业来办，在企业平台进行实施。企业对接人才培养全过程，参与 人才培养方案的制定和实施。涉及到从教学计划、教学环节、课程体系到教学过程、考核评价全过程, 要求 具有操作的可行性和合理性，这是产教融和过程能否顺利实施成功推进的关键。

\section{1. 专业体系和课程体系改革}

生命科学学院将原有的生物技术，生物工程和生物科学三个专业专业纳入学科专业群建设，以服务“国家 高技术生物产业基地”建设和发展需求为切入点，建立人才培养体系。同时，为应对“新工科”建设，及时增设 与产业链需求相关的食品质量与安全和生物信息学新专业, 不断推进学科专业群的整合。健全专业群内教师, 课程、试验实训资源共建共享机制。紧密围绕生物学专业群的特点以及专业建设的指导思想和产教融合内涵, 以培养具有技术创新能力的人才为核心，对各专业的课程体系进行改革。

按照“通识教育与专业教育相结合、理论教学与实践教学相结合、全面素质教育与优秀人才培养相结合、 学生现实需要与终身发展相结合、服务区域经济社会需要与学校（院）可持续发展相结合”的四个结合原则, 科学设置课程体系, 创新人才培养模式, 修订、完善了本专业本科培养方案。通过对考研、地方经济建设需 求及自主创业所需人才的能力要求进行剖析和探讨，对每个课程群进行最优化设置。专业群内所有专业的课 程结构体系分为公共必修课程、专业必修课程和实践教学三种类型。第二个类型中又分别设置专业必修与选 修课程。专业必修课程设置学科基础课程和专业核心课程二个模块。实践教学类型设置基础、专业、综合实 践三个课程模块。分析通识教育课程、专业教育课程和实践教育课程的关系，合理设置专业实践课程比例。 按照“因材施教、强化基础、拓宽口径、优化结构、重视实践、提高素质”的要求，不断深化教学改革，形成以 学生能力培养为核心的人才培养方案。根据目前学生就业（即考研、地方经济建设需求及自主创业等）需求, 对不同层次学生进行分类培养，构建本科专业分流培养的人才培养模式，其中三种类型人才分类培养按照学 术方向、应用专业和特殊需求三种类型分类培养。

\section{2. 采取多元化创新创业教育内容}

对课程体系进行改革，建立创新创业教育课程体系，开展创新创业教育指导及实践课程。在完成人才培 养方案上设置课程的同时，鼓励学生参与教师科研，引导学生参加创业设计竞赛，包括“挑战杯”、国家创新 创业竞赛等, 结合第一课堂与第二课堂开展大学生创新创业教育。不仅对学生普及创新创业知识, 也同时提 高他们创新创业实践能力。

将创新创业教育融入就业指导课已成为本专业创新创业教育的另一主要形式。通过开设就业指导课引导 学生树立就业意识和职业意识, 积极参加实践, 提高专业技能, 从大一开始, 引导学生认识了解本专业特点、 发展方向及所要求的技能, 使学生对就业有较清楚的认识。从大一开始学生进行企业参观访问, 让学生了解 企业生产的概况，感受企业文化。同时引导大学生树立正确的就业观，先就业再择业。同时加强创业教育， 指导毕业生认识创业所必备的素质和条件，如创业知识的储备、资金的准备、技术和兴趣、个人能力等等。 聘请企业富有经验的创业成功者到校为毕业生做创业报告, 让学生从成功者的经历中积累经验, 了解创业的 基本程序，让学生在校期间就能进行创业尝试，培养生的创业意识、创业能力和创业人格。

3. 校内外实践创新平台建设 
充分利用校内校外资源，打造支撑生物学专业群人才培养的创新创业实践协同育人平台。在校内，充分 利用高校重点实验室、省级重点实验室、发酵工程实验室、食品检测和食品开发实验室的软硬件条件，与园 林与建筑学院、物电学院、医药与护理学院、生物物理研究所等单位, 联合成立德州学院生物物理应用技术 联合体及理事会, 依托联合体内的实验实践创新条件, 探索创新和发展相关的校内育人机制, 打造德州学院 生物学优势学科专业群协同育人实践平台。利用学院老师承担的国家自然科学基金和省厅级项目, 在校内协 同育人平台支持下, 大力开展大学生科技创新项目、大学生学科竞赛和课外科技兴趣小组等活动, 提高学生 的创新能力, 学习最新的生物学技术。

在稳定原有基地的基础上，加强企业实践平台建设，不断扩展新的实习基地。在校内协同育人实践平台 的基础上, 学院与德州市进出口商业检验检疫局、德州市药品监督管理局共建了大学生创新创业教育基地, 与希森集团马铃薯国家工程技术中心、克代尔集团、谷神生物科技集团有限公司、保龄宝生物科技有限公司、 龙力生物科技有限公司、德州市生物技术产业联盟、江苏福旦生物医药有限公司合作，加强本专业群校外创 新创业基地的建设，完善校外实践基地。逐步提高基地利用效率和学生实习质量，鼓励老师参与实习基地项 目, 既有助于教师了解实际生产中的技术需求, 又提高了教师的科研能力, 并促进教师的科研成果向实际应 用转化，服务地方经济，同时，也促进了学生较早了解行业对人才的需求方向，为将来就业打下基础。

\section{4. 强化实践教学在教学中的地位}

为更好地培养学生的实践能力, 改变过去重理论、轻实践的课程设置, 做到理论与实践并重, 增加和强 化实践教学, 提高学生进行科学实验和分析解决实际问题的能力。学院坚持科研-教学-实践互通、基础-综合创新多层次能力培养相互衔接、相互促进的培养应用型人才的指导思想, 加大学生专业实验操作技能的培养。 作为实践技能要求比较高的专业, 学院通过实验教学改革提高学生实践技能。以培养应用型创新人才为目标, 满足区域新经济产业对人才的需求，立足当地经济建设，构建培养应用型人才所需的实践训练课程体系。针 对提升和拓展学生从业能力与提高就业率，探讨构建实验能力、自主创新创业能力体系和多元化、应用型实 践训练新体系。

学院通过调研区域产业发展过程中对生物学人才的能力要求, 细化能力指标, 通过课程开设、开放性实 验、认知实习、校内模拟实习、专业实习、毕业实习等实验实训环节实现学生从事企业一线工作的能力构建。 将主干课程的实验课单独开设为一门课，单独计算成绩及学分。并给予组织、管理、场地及资金的配套，使 实践教学与理论教学平行而又相互协调、相辅相成。开展第二课堂实践。学院制定了实验室开放制度, 健全 实验室开放机制, 要求基础教学实验室和科研实验室面向本科教学开放, 学生可以自主设计并实施实验, 也 可以完成大学生科技创新项目和准备生物学科实验技能大赛项目。老师将在科研中积累的新技术、材料和前 沿研究成果适时引入实验及理论教学中。为提高学生实践动手、科学研究和运用理论解决问题的能力提供了 良好支撑平台和条件。

\section{5. 完善“双师型”师资队伍建设}

高校师资队伍一般具有较强的创新能力, 但实践能力和创业能力相对薄弱, 由于现有高校教师的职业特 征, 长期以来教师注重学术研究, 基本上没有在企业工作的经验, 即使个别老师获得相应的技术资格证书, 但对企业生产线的运行和经营管理也不熟悉, 导致“双师型”教师严重不足 ${ }^{[6]}$ 。这一缺陷可以通过产教融合进行 改变, 改善学校老师与企业的关系和企业工程师与高校的关系。高校教师进行企业挂职锻炼, 结合各自专业 
直接与相应的生产企业对接，锤炼自身，提升教师服务企业的能力。同时，邀请企业生产一线的工程师参与 本科教学，形成了实践反哺教学的良好态势。

德州学院通过百名博士下基层活动，在学校层面上协调与企业之间的联系，组织有专业特长的教师深入 企业, 与企业研发人员和技术工人一起参与企业生产，了解企业的技术需求。高校教师通过与企业对接，可 以有机会将最新的研发成果进行转化, 这种对接更加接地气。企业实际生产中的操作经验和隐形知识可以引 入课堂教学。学校层面上, 深入实施人才强校战略, 分层次、有计划做好人才引进工作, 重点引进学科专业 群建设急需的高层次“双师型”人才。

\section{6. 构建创新性应用型人才培养保障措施}

构建科学的教学保障体系, 在生命科学学院成立学科专业群建设领导小组, 学术委员会, 教学督导委员 会, 协调统筹学科专业群建设, 推进教学改革, 教学质量评估任务。定期对实施过程进行调研、督导, 重点 加强过程监控与目标考核, 确保各项建设措施落到实处。落实以学生自我发展为核心的教育质量观, 构建覆 盖人才培养各个环节的质量监控体系。探索建立科学的绩效评价考核体系, 加强过程管理, 完善实验室开放 制度, 强化绩效考核, 及时跟踪指导。定期对各专业建设的进展情况进行考核评估, 并根据考核结果和建设 绩效，在相对稳定支持的基础上实现动态调整。设立应用型专业建设专项资金，支持各专业开展行业调研、 专业协作、课程建设、教材编写、教学改革等。对于专业建设所需的教学仪器、实验设备等, 优先纳入学校 购置计划。同时鼓励各专业发挥自身优势, 通过合作办学、科技成果转化、智力服务等途径, 积极筹措建设 经费。

7. 校企进行深层次互动，服务地方经济

产教融合不只局限于培养服务区域生物产业的高技术人才，随着校企合作的深入，校企之间通过共建研 发中心, 共享实验平台, 科研人员互聘等形式可进行深入合作，解决企业的具体问题。学院与区域龙头生物 企业联合，通过企业项目进学校，建立联合研发中心，聘请企业联合研发兼职教授，积极探索产学研合作新 模式。校内实践创新平台采取多种措施，保障平台设备对企业开放与共享。所有大型仪器均通过德州学院大 型仪器平台对校内外开放, 实现资源共享。联合研发中心以课题或项目的形式组建攻关团队, 坚持“开放、流 动、联合、竞争”的运行机制。建立了完善的人才队伍建设激励机制, 实行课题制和聘用制管理模式。通过设 置开放课题, 聚拢高水平研究人才, 逐步探索将企业技术、管理人员纳入实验室, 加强国内外学术交流与合 作。

近年来联合研发中心开展多项社会服务, 助力山东省新旧动能转换。生命科学学院被评为山东省企校合 作先进单位，并与山东龙力生物科技有限公司、山东江口生物科技有限公司签订合作协议，与企业搭建了人 才培养平台。帮助山东谷神生物科技有限公司申请国家企业技术中心获得成功，与企业共同搭建了技术创新 平台。同德州福临居餐饮集团联合建立食品微生物指标检测标准化实验室, 合作建立了食品微生物检测平台。 与山东中澳控股集团签订联合实验室建设协议, 购置了血红素分离和提纯的中试设备, 实现了学校实验室与 企业生产线的对接。帮助山东中澳集团申请到山东省星火计划重点项目“中澳控股集团有限公司鸭血血红素产 品开发”, 实现了应用研究与企业发展难题的对接。

\section{六、结语}

随着德州地区生物产业的发展，对具有高等教育背景的创新性应用型人才需求量大增，同时，也为地方 
高校培养适应于企业发展的应用型人才高提出了新标准和要求。地方本科院校肩负着为地方培育人才, 促进 地方社会、经济发展的使命。目前, 德州学院正处于转型的关键时期, 机遇与挑战并存。作为地方高校以创 新性应用型人才培养为目标, 培养学生分析解决实际问题能力和创新能力, 这需要我们进一步科学定位专业 方向并从现实性、针对性以及独特性等途径加强专业内涵建设。生命科学学院坚持“创新性应用型”“重基础, 求创新, 重应用”的人才培养理念, 结合地方经济对人才需求的特点, 以培养更高层次生命科学人才为核心, 坚持精品教学战略, 以学生为主体, 教师为主导, 充分发挥学生特长, 培养学生创新能力, 形成了“拓宽知识、 夯实基础、提高创新能力”的本科生培养体系。

编辑: 李楠

基金项目 1.德州学院教研课题项目“以学生为中心”的分子生物学双语教学改革与实践 (JG2018082)；2.教育 部产学合作协同育人项目（201801168029）：生物物理交叉学科创新实验班构建及实践基地创新建设；3.德州 学院教研课题项目：基于省级科研平台的智能生物医疗技术创新实验班（JG2018001）。

\section{参考文献}

1. 吴立保, 曹辉, 宋齐明等. 新时代建设高等教育强国的监测指标体系研究 [J]. 国家教育行政学院学报, 2019(7).

2.周珂, 赵志毅, 李虹. “学科交叉、产教融合”工程能力培养模式探索 [J]. 高等工程教育研究, 2019(3):33-39. 3. 杜亚冰, 楚瑜. 地方本科院校产教融合存在的问题及对策[J]. 教书育人(高教论坛), 2018, No.640(18):14-15. 4. 禹奇,张俊平,张灵，等. 创新性应用型人才：地方重点建设高校培养目标定位[J]. 中国高等教育, 2010(22):4243.

5.张桂春, 唐为民, 张琳琳,高等教育学[M].大连：辽宁师范大学出版社, 2007:154-167

6.董奎玲. 应用型本科专业“双师双能型”师资队伍建设研究[J]. 中国成人教育, 2019(9).

\section{作者简介}

通讯作者宋建, 男, 1980 年出生, 山东菏泽人, 生物学博士, 德州学院生命科学学院教师, 研究方向为分子 生物学; 通讯地址：德州市德城区大学西路 566 号德州学院生命科学学院, 邮政编码: 253023 , 电子信箱: 347748895@qq.com。https://orcid.org/0000-0003-1998-9966。

刘丽霞, 女, 1979 年出生, 山东曹县人, 生物学博士, 德州学院生态与园林建筑学院副院长, 研究方向为植 物生理学; 通讯地址：德州市德城区大学西路 566 号德州学院生态与园林建筑学院, 邮政编码: 253023 , 电 子信箱：99253304@qq.com。https://orcid.org/0000-0002-8663-9360。

曾强成, 男, 1972 年出生, 甘肃高台人, 生物学博士, 德州学院生命科学学院院长, 研究方向为细胞生物物 理学; 通讯地址：德州市德城区大学西路 566 号德州学院生命科学学院, 邮政编码: 253023 , 电子信箱: qiangchengzeng@126.com。https://orcid.org/0000-0002-8879-7434。

收文日期Ｒeceived: 20200220 Accepted: 20200224 Published:20200229

\section{本文引用格式}

宋建, 刘丽霞, 曾强成. 产教融合背景下地方高校创新性应用型人才培养的探索[J].产教融合研究,2020.2(1):125134. DOI:10.6938/IIE.202002_2(1).0017 
Song Jian, Liu Lixia, Zeng Qiangcheng. Exploration on the Cultivation of Innovative Applied Talents in Local Universities under the Background of Industry-Education Integration[J]. Integration of Industry and Education,2020.2(1):125-134. DOI:10.6938/IIE.202002_2(1).0017

\title{
Exploration on the Cultivation of Innovative Applied Talents in Local Universities under the Background of Industry-Education Integration \\ Song Jian Liu Lixia Zeng Qiangcheng
}

Song Jian, Lecturer, College oflife Sciences, Dezhou University, 566 West University Road, Decheng District, Dezhou, Shandong Province, PRC.Email:347748895@qq.com.https://orcid.org/0000-0003-1998-9966.

Liu Lixia, Associate Professor, College of Ecology and Landscape Architecture, Dezhou University, 566 West University Road,, Decheng District, Dezhou, Shandong Province, PRC. Email:996445262@qq.com. https://orcid.org/0000-0002-8663-9360.

Zeng Qiangcheng, Associate Professor, College of life Sciences, Dezhou University, 566 West University Road, Decheng District, Dezhou, Shandong Province,PRC.Email:qiangchengzeng@126.com. https://orcid.org/0000-00028879-7434.

\begin{abstract}
Local colleges and universities should focus on serving regional industries and local economic development, as training base for applied talents with innovative spirit. The fusion of industry and education proposes new guidelines to construct school-enterprise collaborative education platform and integration of industrial chain and academic chain. By using the fusion of industry and education to enhance higher education quality for local colleges and universities, Dezhou University construct the competency-based talent cultivation mechanism from the aspects of reforming the talent training scheme, optimizing the specialty and curriculum system, adopting diversified innovation and entrepreneurship courses, promoting the practice teaching, building platforms for practice and innovation, training "double-skilled" teachers and establishing safeguard measures for talents training. Thus providing guidance and demonstration for the cultivation of applied talents with innovative spirits in local colleges and universities.
\end{abstract}

Keywords: local colleges and universities; fusion of industry and education; applied talents with innovative spirit 